\title{
Does Experience Co-creation (XCC) Change Entrepreneurial Intention?
}

\section{A Longitudinal Study on the Theory of Planned Behavior in UMK Student}

\author{
Firdaus Basbeth $^{1 *}$, Noorshela Che Nawi ${ }^{2}$ \\ ${ }^{1}$ Sekolah Tinggi Manajemen IPMI, DKI Jakarta, Indonesia 12750 \\ ${ }^{2}$ Universiti Malaysia Kelantan, Kelantan, Malaysia 16100
}

\section{ABS T RACT}

Despite the global emphasis on the relevance and potential impacts of entrepreneurship has dramatically increased as a potent economic force, entrepreneurship education has not significantly changed in two decades. Existing approaches to entrepreneurship education are focus is on teaching 'about' entrepreneur and what they do rather than teaching 'for' entrepreneurship. Drawing on the synthesis based on the theory of planned behavior (TPB) by Ajzen (1991), we introduce Experience Co-creation as a new approach to teach entrepreneurship courses based on the concept of experiential learning. The approach for the program was synthesized and adapted from Experience cocreation (XCC) theory mostly used in tourism literature. This study develops a longitudinal framework of student's intention after 3 months of teaching entrepreneurship with a different approach. The result demonstrates that the mean value of personal attitudes, subjective norms, perceived behavioral control and entrepreneurial intention are improved, and the relationship between perceived behavioral control and entrepreneurial intention improved significantly at the end of the course. The result indicates that students' intention is greater after the program than before the class started. This study fills a gap in the entrepreneurship body of knowledge by providing evidence the teaching method moderates the relationship between perceived behavioral control and entrepreneurial intention. This study is an empirical study that uses a SmartPLS3 with data taken from the survey of 220 students in Strategic Entrepreneurship APT-2083 Class L4 \& L5 Sem 22018 /19. The study suggests that universities can gain the highest entrepreneurial intention by introducing the innovative method in teaching entrepreneurship.
\end{abstract}

\section{ART I C LE I N F O}

Article History:

Received : 14-10-2020

Revised : 22-10-2020

Accepted : 26-10-2020

Published : 31-10-2020

Keywords:

Entrepreneurial Intention

Perceived Behavioral Control

Experience co-Creation
*Corresponding Author E-mail:

firdaus.basbeth@ipmi.ac.id 
Copyright (C) 2020 Authors. This is an open access article distributed under the Creative Commons Attribution License, which permits unrestricted use, distribution, and reproduction in any medium, provided the original work is properly cited.

\section{INTRODUCTION}

The Global Entrepreneurship Monitor (GEM) Report 2018, stated that Malaysia's Total Earlystage entrepreneurial activity (TEA) rate is the lowest in the region. The percentage of individuals who are in the process of starting or are already running new businesses in Malaysia demonstrates that fewer people are pursuing entrepreneurial opportunities and innovative initiatives. Moreover, according to the Malaysian Employers Federation (2018), more than 200,000 graduates from institutions of higher learning in the country are still unable to get a job even after graduating in the last two years. Become an entrepreneur should be an alternative solution to boost the economy. Students lack the interest to start their ventures, and its contributing factors may derive from weakness to offer transformative teaching and learning, along with the transformation tool in the teaching and learning itself. As Timmons, Spinelli, and Tan (2004) said that entrepreneurship is "not just about a new company, capital, job formation, nor innovation, nor creativity, nor disruptions, it is also about fostering human spirit and improving humankind". The role of educators now is more to unlock the entrepreneurial spirit of the student, increase entrepreneurial intention, and build a practice environment. Entrepreneurship education has to be expanded to include the development of entrepreneurial mindsets, and the promotion of creativity to spark a business idea and entrepreneurial culture (Kuratko, 2003) Entrepreneurship education needs to be experiential, enabling students to learn through entrepreneurship (Gibb, 2002)

Despite the global emphasis on the relevance and potential impacts of entrepreneurship has dramatically increased as a potent economic force, entrepreneurship education has not significantly changed in two decades. Existing approaches to entrepreneurship education are focus is on teaching 'about' entrepreneur and what they do rather than teaching 'for' entrepreneurship (Wales, Patel, Parida, \& Kreiser, 2013). Teaching about entrepreneurs emphasizes scholarly consideration of the characters of entrepreneurs and what they do to launch a new venture, from opportunity identification to the start-up process. This contrasts with teaching 'for' entrepreneurship, where the specific objective is to stimulate entrepreneurship amongst students. There is remarkably little discussion in the literature on what form experiential education should take, to increase entrepreneurial intention. As a result, little evidence supports the experiential approaches to entrepreneurial intention. We introduce an experienced cocreation (XCC) program to create an experience together with a classmate and lecturer to engage them through a process of entrepreneurship in a fun environment to overcome a fear of failure that has always been the factors that could deter the drive to start a business. In strategic literature, the term co-creation or co-innovation refers to the fourth stage of evolution in innovation (innovation 4.0) which allows collaboration with other parties including customer, and individuals inside or outside the organization to produce value or experiences for all stakeholders (von Hippel, Ogawa, \& PJ de Jong, 2011). In the learning process, the essence of co-creation in the entrepreneurship class is that experiences and values created together will create ownership and improve student engagement and in turn, it will increase their intention to become an entrepreneur.

The XCC activities series in the program was designed together with the student based on the syllabus and learning objectives that the course wants to achieve. A series of activities were offered to them and through the selection process together, two activities have been chosen, namely "we are a consultant" and "my new venture". In the first activities, "we are a consultant" students will have to choose medium size company they are 
interested in, prepare to interview the company, learn how firms grow, and how to survive through changes in the external environments. The student not only will report the findings and consult with the lecturer but also give the firms their breakthrough or novelty suggestions from their perspective to the firm they are involved in. The lecturer provides guidance of theory and a set of questionnaires to be used on a weekly basis to learn interactively with the management of the company. The owner of the firm was also invited to the class to share and recognize a student for their works and accomplishment. The second activities include an individual task to create their own business by creating a blog of their interest and hobbies, identity opportunity might emerge, and marketing their product or service digitally using social media platforms like Instagram and Facebook. They can approach their classmate to follow, to like, and finally monetize their business ideas. Both activities offer an entrepreneurial experience journey and still maintaining fun in the classroom by running online quizzes and give away gifts for the winner. As fun theory by Volkswagen in 2010 said that novelty and fun makes things interesting and make people feel good at the same time (Camilleri, 2015). When things are interesting and the student feels good about it, they want to do things and engage in the program, and when they are engaged, they feel encouraged and entrepreneurial intention will grow. This program is intended as a contribution towards filling the experiential learning gaps. It has two objectives, firstly, to evaluate the student's intention before and after the program induced. Secondly, to analyze the effectiveness of this experiential approach to entrepreneurship education and how it might be developed further.

\section{LITERATURE REVIEW}

\section{Theory of Planned Behaviour (TPB)}

TPB has been the dominant theoretical approach to guide research related behavior for the past three decades (Ajzen, 2015). The theory is well recognized amongst researchers and is also familiar to many students, practitioners, and policy-makers (Köykkä et al., 2019). The most frequently used theoretical framework in major studies of entrepreneurial intention is the Theory of Planned Behavior (Gelderen, 2016). The roots of TPB can be found in the model of (Bird, 1988) about entrepreneurial intention; factors that determine intentions as presented by Gelderen (2016) which are: attitude subjective norms, perceived behavioral control, perceived control liability of behavior self-efficacy, and perceived desirability and feasibility. Though criticized as a model with a limited predictive validity in recent years by some scholars, e.g.Sniehotta, Presseau, and Araújo-Soares (2015), TPB still stands as a validated solution to the construction of research in entrepreneurial intent. Entrepreneurship is considered as a type of planned behavior for which the intention models are ideally convenient in understanding the business venture formation intentions (Krueger Jr, Reilly, \& Carsrud, 2000). Wales, Patel, Parida, and Kreiser (2013) characterized entrepreneurial intention as the eagerness of people to perform entrepreneurial conduct, to lock in in entrepreneurial activity, to be self-employed, or to set up unused trade. Whereas, agreeing to (Ajzen, 1991) entrepreneurial intention is the prompt predecessor of conduct towards entrepreneurial. In this context, research is based on the constructs of the theory of planned behavior.

\section{Personal Attitude and Entrepreneurial Intention}

Personal attitude (PA) is the degree to which the person holds a positive or negative individual attitude around being a business person (Liñán, 2004). Personal attitude moreover alludes to an individual's recognition of the allure to perform an entrepreneurial movement (Tshikovhi \& Shambare, 2015) The more positive the conclusion result is the way better and more discerning recognitions to carry out certain practices. While to Fayolle, Liñán, and Moriano (2014) personal attitude could be a degree of commitment towards beginning entrepreneurship and the will to cost towards entrepreneurial activities. (Liñán, Rodríguez-Cohard, \& Rueda-Cantuche, 2011) state that personal attitude is impacted by the entirety of all the feelings and sentiments of the 
fulfillment of a person experienced amid the learning stage of the examined subject. Walter and Dohse (2009) found that the individual state of mind toward the conduct has a coordinate and positive impact on entrepreneurial intention. Agreeing to it, Wales et al. (2013) outlined the result of a solid impact on the eagerly in which the behavior is a variable closely related to a variety of attitude leads entrepreneurial intention. Other than that, (Krueger Jr et al., 2000) tested the link of personal attitude to intentions and found that a positive impact on personal attitude to entrepreneurial intention. Based on the above explanation, the below hypothesis is shaped;

H1: Personal attitude positively influence entrepreneurial intention

\section{Subjective Norm and Entrepreneurial Intention} Subjective norms according to Sniehotta et al. (2015), is the view of a person affected by others. According to (Wedayanti \& Giantari, 2016), subjective norms are the perceives that are considered imperative by people who encourage the person to perform or not perform certain practices and inspiration by a readiness to do or not do something that was considered imperative. Ajzen (1991) characterizes that subjective norms have alluded to the discernment that "reference people" would favor the choice to be an entrepreneur. Whereas according to Sousa, Cruz, and Wilks (2018), the subjective norm is the individual's conviction in complying with the information or recommendations of individuals around them to take an interest in different exercises. Based on these three definitions, in this study, we use the definition of subjective standards developed by (Ajzen, 2001) subjective norm is the recognition of reference individuals that would favor the choice in business career. According to Ajzen (1991) a pressure from family, companions and society impact one's conduct to be a business person. Ajzen (1991) moreover, portrays these subjective norms may come from individuals or environments that are near to us or ordinary things that we frequently do. This coincides to Kolvereid and Bullvag (1996) statement that family influencing entrepreneurial intention. Kolvereid and Isaksen (2006) found that subjective norm related to entrepreneurial intention. However, Liñán and Chen (2009) found that there was no critical relationship between subjective norm and entrepreneurial intention. Yordanova and Tarrazon (2010) found that the stronger the subjective norm on entrepreneurial conduct, the more grounded the individual's entrepreneurial intention. Based on the accumulated evidence showing on the effect of subjective norms on entrepreneurial intention, this study seeks to test the following hypothesize:

H2: Subjective norm positively influences firm performance

\section{Perceived Behavioural Control and Entrepreneurial Intention}

Ajzen (2002) characterizes perceived behavioral control (PBC) as a calculation on reviving to the affluence or trouble performing the conduct seen by individuals and it is reflecting past involvement as well as expects hindrance and obstacles. This definition suggests that perceived behavioral control reflect a level of confidence to perform an activity (Ajzen, 2002) moreover considers that perceived behavioral control could be a concept to some degree more extensive than self-efficacy. It is incorporate to a degree of controllability (the degree to which effectively performing the conduct is up to the individual). Perceived behavioral control is specified within the shape of self-efficacy is a condition where individuals accept that conduct is simple or troublesome to do (Díaz-García, Sáez-Martínez, \& JiménezMoreno, 2015). Perceived behavioral control is the recognition of a person of the ease or trouble in carrying out the assignment in opening a new company (Díaz-García et al., 2015). Based on Samuel, Ernest, and Awuah (2013) definition, perceived behavioral control is described as a control alludes to the degree to which the person feels able of performing the conduct. The more prominent the feeling of behavioral control, the more grounded will be deliberate to perform the conduct. Pihie and Akmaliah (2009); Ruhle, Mühlbauer, Grünhagen, and Rothenstein (2010) recommended that perceived behavioral control 
has a positive impact on a student's entrepreneurial intention. In any case, Elfving, Brännback, and Carsrud (2009) and Raposo and Do Paço (2011)contended that the more prominent the person accepts that he can be a fruitful business person with a tall likelihood of succeeding; the more grounded in the entrepreneurial intention. Based on the accumulated evidence showing on the effect of perceived behavioral control on entrepreneurial intention, this study seeks to test the following hypothesize:

H3: Subjective norm positively influences firm performance

\section{The Moderating effect of Teaching Method}

The link between PA, SN, PBC, and entrepreneurial intention has been extensively researched in the past few years (Hyder, Azhar, Javaid, \& Rehman, 2011; Pihie \& Bagheri, 2009). Most studies find that the relationship between $\mathrm{PA}, \mathrm{SN}, \mathrm{PBC}$, and EI is highly dependent on contextual conditions (Boyles, 2012). For example, previous research has assessed the role of gender (Yordanova \& Tarrazon, 2010) , environmental attributes (Brush, Kolvereid, Widding, \& Sorheim, 2010) , social capital (Stam \& Elfring, 2008), support system (Wales et al., 2013), and government support (Van Doorn, Jansen, Van den Bosch, \& Volberda, 2013). In this study, we argue previously that PA, SN, PBC positively influence entrepreneurial intention, however, it also depends on the teaching method use that influences the student to change the relationship between $\mathrm{PA}, \mathrm{SN}, \mathrm{PBC}$, and entrepreneurial intention, therefore given these arguments, we have set our hypothesis as:

H4: Teaching method positively mediates the relationship between $\mathrm{OL}$ and firm performance

\section{RESEARCH METHOD}

This study utilized a longitudinal survey of a sample in the University Malaysia Kelantan course of Strategic Entrepreneurship APT-2083 Class L4 \& L5 Sem 2 2018/19. In total, 250students were attended the class and 220 responses were received. The present study employs a questionnaire survey approach to collect data, and all independent and dependent variables require five-point Likert-style responses ranged from 1 = "strongly disagree", through 3 = "neutral" to 5 = "strongly agree". Survey Questionnaires are designed in light of the theoretical background of TPB (Ajzen, 1991).To test the model, PLS-SEM will be employed using SmartPLS3 software. This tool is particularly suitable for small samples with complex models; a prediction-oriented method that does not require strong theory (Henseler et al., 2014).

\section{RESULT}

\section{Measurement model evaluation}

Our model using two reflective measurements, and the criteria for reflective measurement models evaluation includes 1) internal consistency 2) convergent validity 3) discriminant validity (Hair Jr, Hult, Ringle, \& Sarstedt, 2014). The measurement model shown in Figure 1 shows that all outer loading is above 0.7. The result indicates internal consistency and reliability, shown by Cronbach's Alpha and composite reliability are above 0.7 . For convergent validity, the outer loadings are greater than 0.7 , and yield an AVE higher than 0.5 indicate the convergent validity criterion is fulfilled.

To establish discriminant validity, we evaluate the cross-loading and Fornell-Larcker, HTMT, and observed that all criterion was fulfilled. Further, we tested whether the HTMT values are significantly different from 1, therefore discriminant validity is established.

\section{Structural model evaluation and hypothesis testing}

The basic criteria for evaluating the structural model in PLS-SEM are the collinearity (VIF), path coefficient, the level of (R2), the (f2)effect size, the predictive relevant (Q2), and the q2 effect size (Hair Jr et al., 2014). From Figure 1 it can be seen the R2 which indicates variance accounted for variable endogenous, indicate that the coefficient of determination R2of EI is 0.584 (substantial). The algorithm reported that inner 


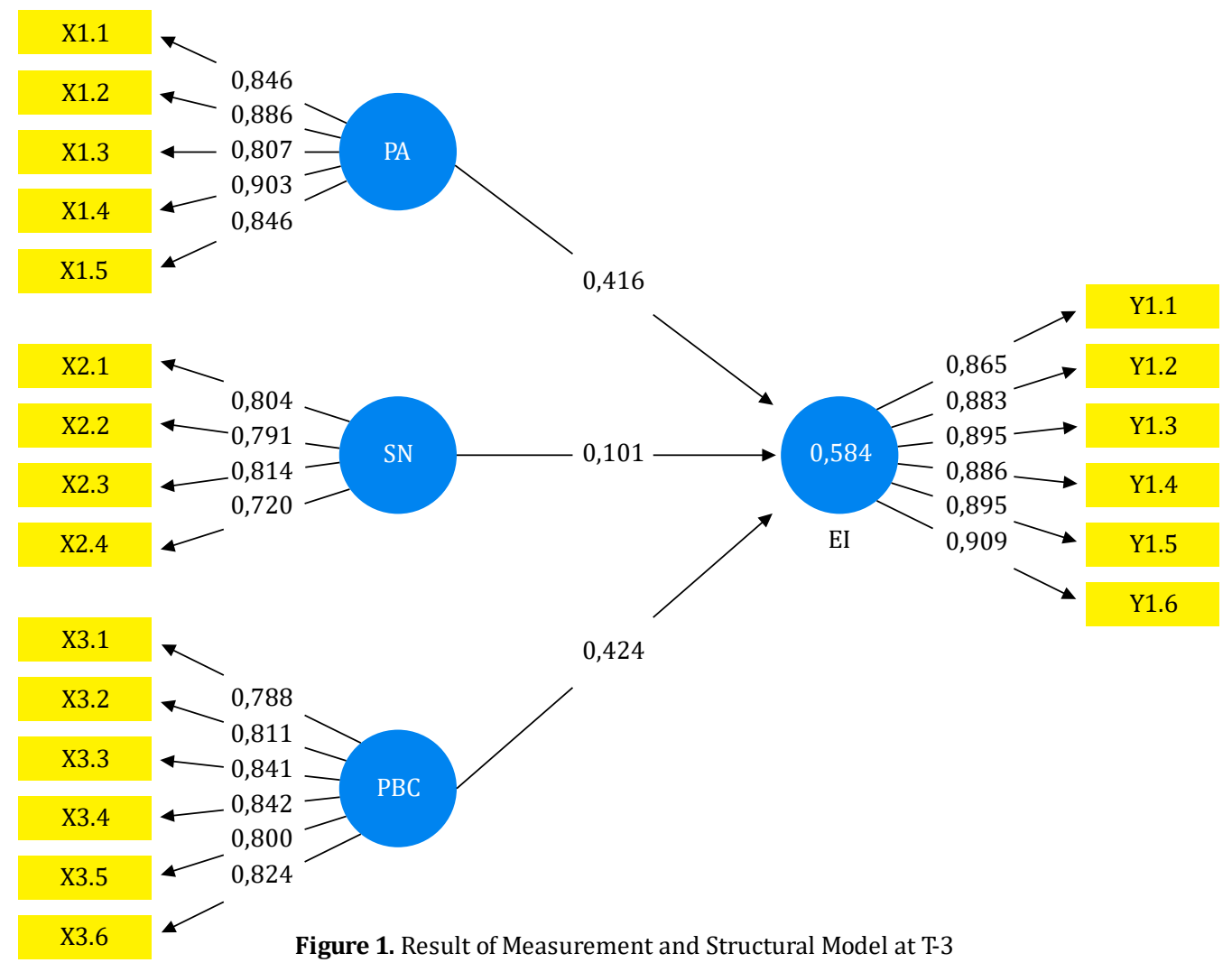

VIF values are below 5 , indicate that all construct free from collinearity problem. Path coefficient and significance of the relationship were obtained from the bootstrapping report from the SmartPLS3. Based on the bootstrap resampling procedure with 5000 subsamples, we summarized the result in Table 1

From the table above we can say that the strongest relationship is between PBC and EI (0.424) which is significant with $t$ value 97.115 and $p$ values 0.000 , with 95\% confidence interval doesn't include 0 . The result showed that PA has a positive impact on EI with a high value of path coefficient 0.416, t-value, and p-value (97.299, and 0.000), and zero doesn't fall into the confidence interval (0.927, 0.971) means Hypothesis 1 is supported.
SN has a weak positive relation to EI, showed by a low value of path coefficient (0.101). The t-stats and p-value $(2.933$, and 0.003$)$ reinforced by the confidence interval bias-corrected $(0.145,0.854)$ indicate that Hypothesis 2 is supported. Finally, PBC has a positive effect and is significantly related to the entrepreneurial intention with path coefficient 0.423 , and t-stats and p-value (2.368, and 0.018), therefore Hypothesis 3 is supported. To test the moderating role of the teaching method, we calculate and test the measurement model and structural model after the course (Figure 2).

Following the same procedures applied in evaluating the research model, to get the result. All value fulfills the criterion set on the PLS-SEM

Table 1. Result of Hypothesis testing

\begin{tabular}{ccccccc}
\hline \multirow{2}{*}{0.861} & \multirow{2}{*}{ Path coefficient } & \multirow{2}{*}{ T value } & P Values & \multicolumn{2}{c}{ Confidence interval bias corrected } & \multirow{2}{*}{ Hypothesis } \\
\cline { 5 - 6 } & & & & $2.5 \%$ & $97.5 \%$ & \\
\hline $\mathrm{PA} \rightarrow \mathrm{EI}$ & 0.416 & 97.299 & 0.000 & 0.927 & 0.971 & H1 Supported \\
\hline $\mathrm{SN} \rightarrow \mathrm{EI}$ & 0.101 & 2.933 & 0.003 & 0.145 & 0.854 & H2 Supported \\
\hline $\mathrm{PBC} \rightarrow$ EI & 0.424 & 2.368 & 0.018 & 0.100 & 0.810 & H3 Supported \\
\hline
\end{tabular}

Note: *Significant at 0.05(1-tailed) 
model, with a significant improvement on the impact of PBC to EI (0.468) compare to the T-3 path value PBC to EI (0.424). The mean average of the variable before and after the implementation of XCC method is shown in Figure 3 below.
As can be seen in Figure 3, the mean value of PA, $\mathrm{SN}, \mathrm{PBC}$, and $\mathrm{EI}$ are all improving in $\mathrm{T}$ time compare to the performance of $\mathrm{T}-3$. The result shows that in Feb (T-3) average mean of entrepreneurial intention is 3.72 and in May 2019
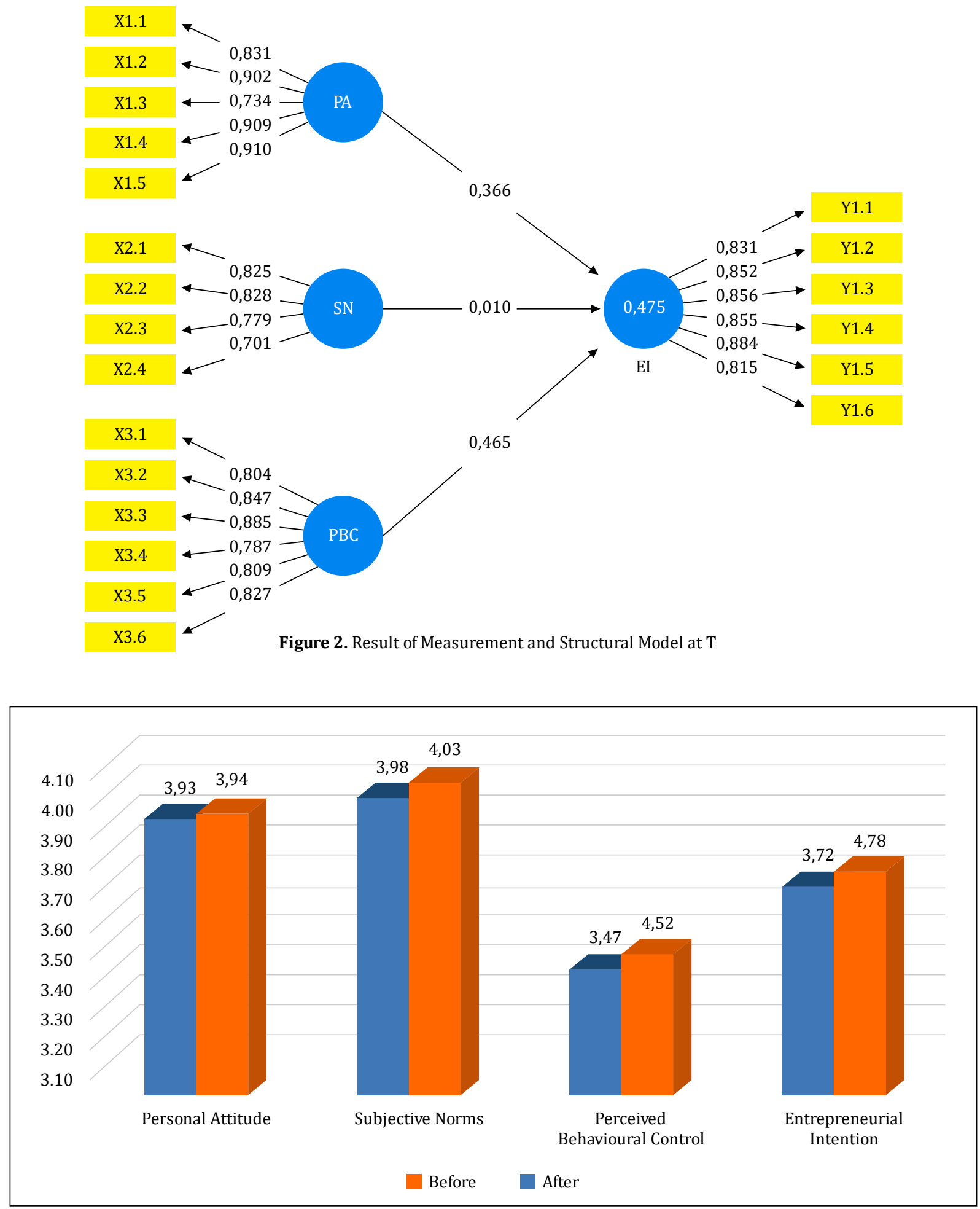

Figure 3. Mean value of PA, SN, PBC, and EI 
( $\mathrm{T}$ after the program) the mean is 3.78. Perceived behavioral control increase from 3.47 to 3.52 . The correlation between the contributing factor also confirmed that with the insertion of experiential learning, the relationship between perceived behavioral control and entrepreneurial intention improved significantly.

\section{DISCUSSION AND RESEARCH IMPLICATION}

This study analyses entrepreneurial intention, factors influencing it, and the moderating role of the teaching method. On the relationship between PA and EI, the findings of the current study were consistent with several previous studies regarding the relationship between personal attitude and entrepreneurial intention, by Walter and Dohse (2009); Samuel et al. (2013) found understanding PA significantly related to EI. The relationship between the male student's Subjective Norm to entrepreneurial intention has not supported the hypothesis. The finding is consistent with Liñán and Chen (2009) who found a relationship between subjective norm and entrepreneurial intention. The relationship of perceived behavioral control to entrepreneur intention is significant, which supported Tshikovhi and Shambare (2015);Pihie and Akmaliah (2009); Ruhle et al. (2010) previous study. On the moderating effect of the teaching method, we found that there is a moderating effect of teaching methods especially on the relationship between perceived behavioral control and entrepreneurial intention. This can be interpreted that student perception of their ability to become an entrepreneur is improving.

The result suggests using XCC teaching method in teaching entrepreneurship courses. The implication for the university is that the academic team needs to review the learning objectives and activities in the entrepreneurship syllabus to be more experiential. They are a lot of options to be used, for example, to include business plan and business pitching competition, student internship in a start-up project, creating new project and crowd finding activities. The existing program entrepreneur week activities which allow student practicing small business in a group during semester break may be enriched to include innovation and inviting industries to collaborate in the event. To support the change a series of prerequisites workshops in digital marketing should be commenced to help students create content and to learn segmentation, targeting, and positioning using digital ads google ads, Instagram, and Facebook ads. Guidance on how to create a free blog, websites, and create content should also be ready for the class practicing.

\section{CONCLUSION}

The current study found entrepreneurial intention levels among students in UMK is moderate. A positive significant predictive relationship was found between personal attitude with entrepreneurial intention. A significant relationship was found between subjective norm and entrepreneurial intention, and between perceived behavioral control and entrepreneurial intention. There was a moderating effect of the teaching method used on the relationship between personal attitude and entrepreneurial intention, and between perceived behavioral control to entrepreneurial intention.

There are some suggestions for future research based on findings from the current study. Although the results are positive for all of the relationship to entrepreneurial intentions, subjective norms have the weakest path coefficient. The factors contributing to this may come from the use of questionnaires. A different style to measure subjective norm is possible to adapt to give a slightly different result. An interesting study could examine external factors variables such as academic and financial support as a moderator to see whether the strength of relationship change with the level of academic and financial support applied in the entrepreneurship course. Another possibility a study can be done by using the level of the program as a control variable and compare the result to see differences between MBA and BBA students. 


\section{REFEREN CES}

Ajzen, I. (1991). The theory of planned behavior. Organizational behavior and human decision processes, $50(2), 179-211$.

Ajzen, I. (2001). Nature and operation of attitudes. Annual review of psychology, 52(1), 27-58.

Ajzen, I. (2002). Perceived behavioral control, self-efficacy, locus of control, and the theory of planned behavior 1. Journal of applied social psychology, 32(4), 665-683.

Ajzen, I. (2015). The theory of planned behaviour is alive and well, and not ready to retire: a commentary on Sniehotta, Presseau, and Araújo-Soares. Health Psychology Review, 9(2), 131-137.

Bird, B. (1988). Implementing entrepreneurial ideas: The case for intention. Academy of management Review, 13(3), 442-453.

Boyles, T. (2012). 21st century knowledge, skills, and abilities and entrepreneurial competencies: A model for undergraduate entrepreneurship education. Journal of Entrepreneurship Education, 15, 41.

Brush, C. G., Kolvereid, L., Widding, L. O., \& Sorheim, R. (2010). The life cycle of new ventures: Emergence, newness and growth: Edward Elgar Publishing.

Camilleri, J. (2015). Youth attitudes towards the fun theory: how to implement and promote proenvironmental behaviour. University of Malta.

Díaz-García, C., Sáez-Martínez, F., \& Jiménez-Moreno, J. (2015). Assessing the impact of the "Entrepreneurs" education programme on participants' entrepreneurial intentions. International Journal of Educational Technology in Higher Education, 12(3), 17-31.

Elfving, J., Brännback, M., \& Carsrud, A. (2009). Toward a contextual model of entrepreneurial intentions. In Understanding the entrepreneurial mind (pp. 23-33): Springer.

Fayolle, A., Liñán, F., \& Moriano, J. A. (2014). Beyond entrepreneurial intentions: values and motivations in entrepreneurship. International Entrepreneurship and Management Journal, 10(4), 679-689.

Gelderen, M. v. (2016). Entrepreneurial autonomy and its dynamics. Applied Psychology, 65(3), 541-567.

Gibb, A. (2002). In pursuit of a new 'enterprise'and 'entrepreneurship'paradigm for learning: creative destruction, new values, new ways of doing things and new combinations of knowledge. International journal of management reviews, 4(3), 233-269.

Hair Jr, Hult, Ringle, \& Sarstedt. (2014). A primer on partial least squares structural equation modeling (PLS-SEM): Sage Publications.

Henseler, J., Dijkstra, T. K., Sarstedt, M., Ringle, C. M., Diamantopoulos, A., Straub, D. W., . . Calantone, R. J. (2014). Common beliefs and reality about PLS: Comments on Rönkkö and Evermann (2013). Organizational Research Methods, 17(2), 182-209.

Hyder, A., Azhar, A., Javaid, A., \& Rehman, M. (2011). Entrepreneurial intentions among business students in Pakistan. Journal of Business Systems, Governance and Ethics, 5(2).

Kolvereid, L., \& Bullvag, E. (1996). Growth intentions and actual growth: The impact of entrepreneurial choice. Journal of enterprising Culture, 4(01), 1-17.

Kolvereid, L., \& Isaksen, E. (2006). New business start-up and subsequent entry into self-employment. Journal of business venturing, 21(6), 866-885.

Köykkä, K., Absetz, P., Araújo-Soares, V., Knittle, K., Sniehotta, F. F., \& Hankonen, N. (2019). Combining the reasoned action approach and habit formation to reduce sitting time in classrooms: Outcome and process evaluation of the Let's Move It teacher intervention. Journal of Experimental Social Psychology, 81, 27-38.

Krueger Jr, N. F., Reilly, M. D., \& Carsrud, A. L. (2000). Competing models of entrepreneurial intentions. Journal of business venturing, 15(5-6), 411-432.

Kuratko, D. F. (2003). Entrepreneurship education: Emerging trends and challenges for the 21st century. White Paper, US Association of Small Business Education, 22(2003), 124-136. 
Firdaus Basbeth, Noorshela Che Nawi / Does Experience Co-creation (XCC) Change Entrepreneurial Intention? A Longitudinal Study on the Theory of Planned Behavior in UMK Student / 184 - 193

Liñán, F. (2004). Intention-based models of entrepreneurship education. Piccolla Impresa/Small Business, 3(1), 11-35.

Liñán, F., \& Chen, Y. W. (2009). Development and cross-cultural application of a specific instrument to measure entrepreneurial intentions. Entrepreneurship theory and practice, 33(3), 593-617.

Liñán, F., Rodríguez-Cohard, J. C., \& Rueda-Cantuche, J. M. (2011). Factors affecting entrepreneurial intention levels: a role for education. International Entrepreneurship and Management Journal, $7(2), 195-218$.

Pihie, Z. A. L., \& Akmaliah, Z. (2009). Entrepreneurship as a career choice: An analysis of entrepreneurial self-efficacy and intention of university students. European journal of social sciences, 9(2), 338349.

Pihie, Z. A. L., \& Bagheri, A. (2009). Developing future entrepreneurs: A need to improve science students entrepreneurial participation. International journal of Knowledge, Culture and Change management, 2.

Raposo, M., \& Do Paço, A. (2011). Entrepreneurship education: Relationship between education and entrepreneurial activity. Psicothema, 23(3), 453-457.

Ruhle, S., Mühlbauer, D., Grünhagen, M., \& Rothenstein, J. (2010). The heirs of Schumpeter: An insight view of students' entrepreneurial intentions at the Schumpeter School of Business and Economics. Retrieved from

Samuel, Y. A., Ernest, K., \& Awuah, J. B. (2013). An assessment of entrepreneurship intention among Sunyani Polytechnic Marketing students. International Review of Management and Marketing, 3(1), 37.

Sniehotta, F. F., Presseau, J., \& Araújo-Soares, V. (2015). On the development, evaluation and evolution of health behaviour theory. Health Psychology Review, 9(2), 176-189.

Sousa, P., Cruz, J. N., \& Wilks, D. C. (2018). Entrepreneurial intentions of law students: The moderating role of personality traits on attitude's effects. Journal of Entrepreneurship Education, 21(3), 1-13.

Stam, W., \& Elfring, T. (2008). Entrepreneurial orientation and new venture performance: The moderating role of intra-and extraindustry social capital. Academy of Management Journal, 51(1), 97-111.

Timmons, J. A., Spinelli, S., \& Tan, Y. (2004). New venture creation: Entrepreneurship for the 21st century (Vol. 6): McGraw-Hill/Irwin New York.

Tshikovhi, N., \& Shambare, R. (2015). Entrepreneurial knowledge, personal attitudes, and entrepreneurship intentions among South African Enactus students. Problems and Perspectives in Management(13, Iss. 1 (contin.)), 152-158.

Van Doorn, S., Jansen, J. J., Van den Bosch, F. A., \& Volberda, H. W. (2013). Entrepreneurial orientation and firm performance: Drawing attention to the senior team. Journal of product innovation management, 30(5), 821-836.

von Hippel, E. A., Ogawa, S., \& PJ de Jong, J. (2011). The age of the consumer-innovator.

Wales, W. J., Patel, P. C., Parida, V., \& Kreiser, P. M. (2013). Nonlinear effects of entrepreneurial orientation on small firm performance: the moderating role of resource orchestration capabilities. Strategic Entrepreneurship Journal, 7(2), 93-121.

Walter, S. G., \& Dohse, D. (2009). The interplay between entrepreneurship education and regional knowledge potential in forming entrepreneurial intentions. Retrieved from

Wedayanti, N., \& Giantari, I. (2016). Peran Pendidikan Kewirausahaan Dalam.

Yordanova, D. I., \& Tarrazon, M.-A. (2010). Gender differences in entrepreneurial intentions: evidence from Bulgaria. Journal of Developmental Entrepreneurship, 15(03), 245-261. 